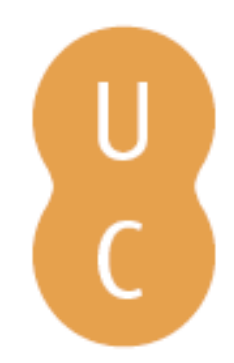

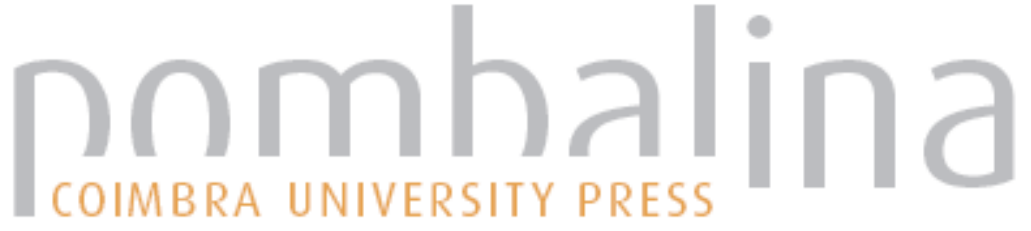

\section{Desenvolvimento rural: novos desafios e novas oportunidades}

\author{
Autor(es): $\quad$ Marques, Hélder; Silva, Ângela \\ Publicado por: Imprensa da Universidade de Coimbra \\ URL \\ persistente: URI:http://hdl.handle.net/10316.2/30819 \\ DOI: $\quad$ DOI:http://dx.doi.org/10.14195/978-989-26-0244-8_40
}

Accessed : $\quad$ 26-Apr-2023 14:28:25

A navegação consulta e descarregamento dos títulos inseridos nas Bibliotecas Digitais UC Digitalis, UC Pombalina e UC Impactum, pressupõem a aceitação plena e sem reservas dos Termos e Condições de Uso destas Bibliotecas Digitais, disponíveis em https://digitalis.uc.pt/pt-pt/termos.

Conforme exposto nos referidos Termos e Condições de Uso, o descarregamento de títulos de acesso restrito requer uma licença válida de autorização devendo o utilizador aceder ao(s) documento(s) a partir de um endereço de IP da instituição detentora da supramencionada licença.

Ao utilizador é apenas permitido o descarregamento para uso pessoal, pelo que o emprego do(s) título(s) descarregado(s) para outro fim, designadamente comercial, carece de autorização do respetivo autor ou editor da obra.

Na medida em que todas as obras da UC Digitalis se encontram protegidas pelo Código do Direito de Autor e Direitos Conexos e demais legislação aplicável, toda a cópia, parcial ou total, deste documento, nos casos em que é legalmente admitida, deverá conter ou fazer-se acompanhar por este aviso.

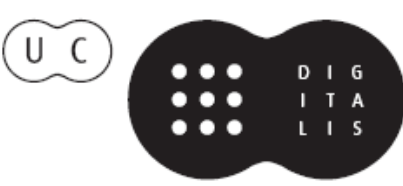




\section{TRUNFOS DE UMA}

\section{EOGRAFIA ACIVA}

\section{DESENVOLVIMENTO LOCAL,}

AMBIENTE,

ORDENAMENTO

E TECNOLOGIA

Norberto Santos

Lúcio Cunha

COORDENAÇÃO 
Hélder Marques, Ângela Silva

Faculdade de Letras da Universidade do Porto/CEGOT

\section{DESENVOLVIMENTO RURAL: NOVOS DESAFIOS E NOVAS OPORTUNIDADES}

\section{COALESCÊNCIA E EXCENTRICIDADE: A DORSAL PROBLEMA BAIXO TÂMEGA}

Parece ser consensual, a julgar quer pelos resultados de diversos estudos relativamente recentes, no âmbito da investigaçáo em Geografia ou de outras ciências sociais, quer pela leitura de diversos diagnósticos, nomeadamente nos incluídos em instrumentos de planeamento territorial, a exemplo do PROT- Norte ou do PNPOT, sublinhar a existência de um território que na Regiáo Norte se destaca negativamente por múltiplas e diversas exclusóes e de que fazem parte a maioria dos municípios que constituem a NUT III Tâmega. O mesmo transparece noutros documentos, a exemplo de projectos ou acçóes de intervenção que visam a qualificação social e territorial ${ }^{1}$.

Figura 1 - Densidade populacional por subsecção em 2001

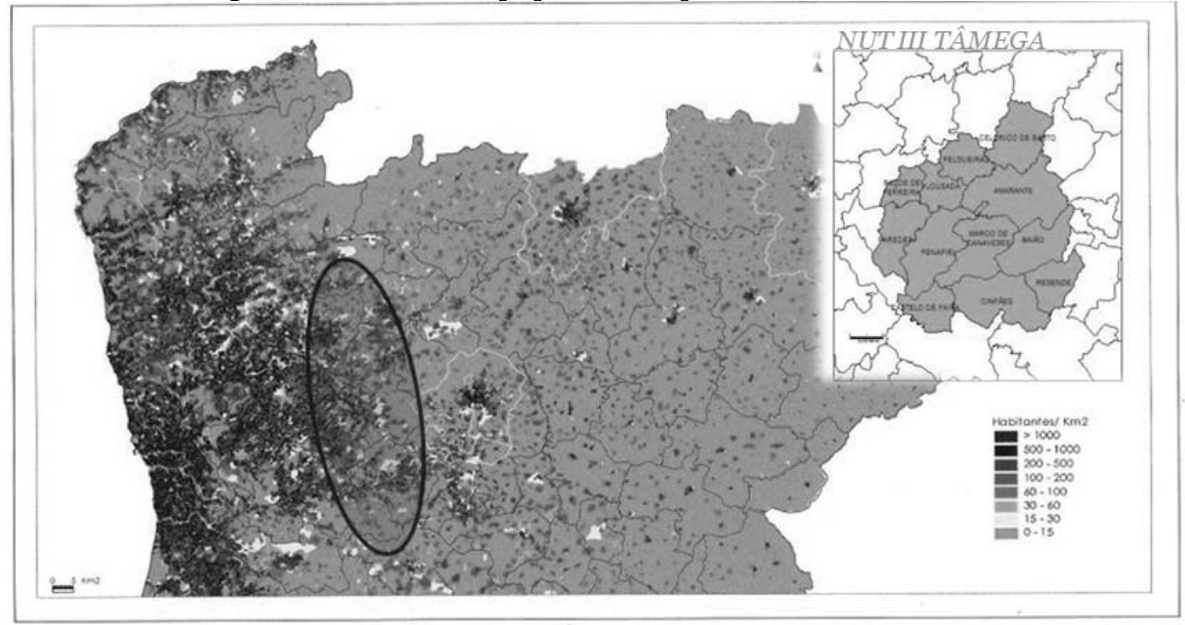

Fonte: adaptado - Teresa Sá Marques (2004); INE (2001)

Ainda que a NUT III Tâmega, pela sua heterogeneidade, se enquadre de forma diversa e multifacetada nas dinâmicas de mobilidade e de territorialização do trabalho características

\footnotetext{
${ }^{1}$ Quartenaire Portugal (2008); CEDRU (2008)
} 
do Arco Metropolitano do Noroeste de Portugal, à sua posição no território, num misto de coalescência e excentricidade, acresce ainda uma textura geográfica específica quer quanto aos principais traços da geomorfologia (declives acentuados ou sistemas de socalcagem das terras de cultivo) quer quanto às tipologias de povoamento dominantes, fluindo entre urbanidades difusas e povoamento rural disperso, ainda que, aqui ou ali, nodolizado por núcleos urbanos de pequena e, sobretudo, muito pequena dimensão. Em 2001, foram registadas 37462 pessoas como populaçáo isolada, apenas três aglomerados populacionais tinham mais de 10000 habitantes, totalizando 36451 pessoas, residindo a maioria (405528) em núcleos de dimensão inferior a 2000 habitantes.

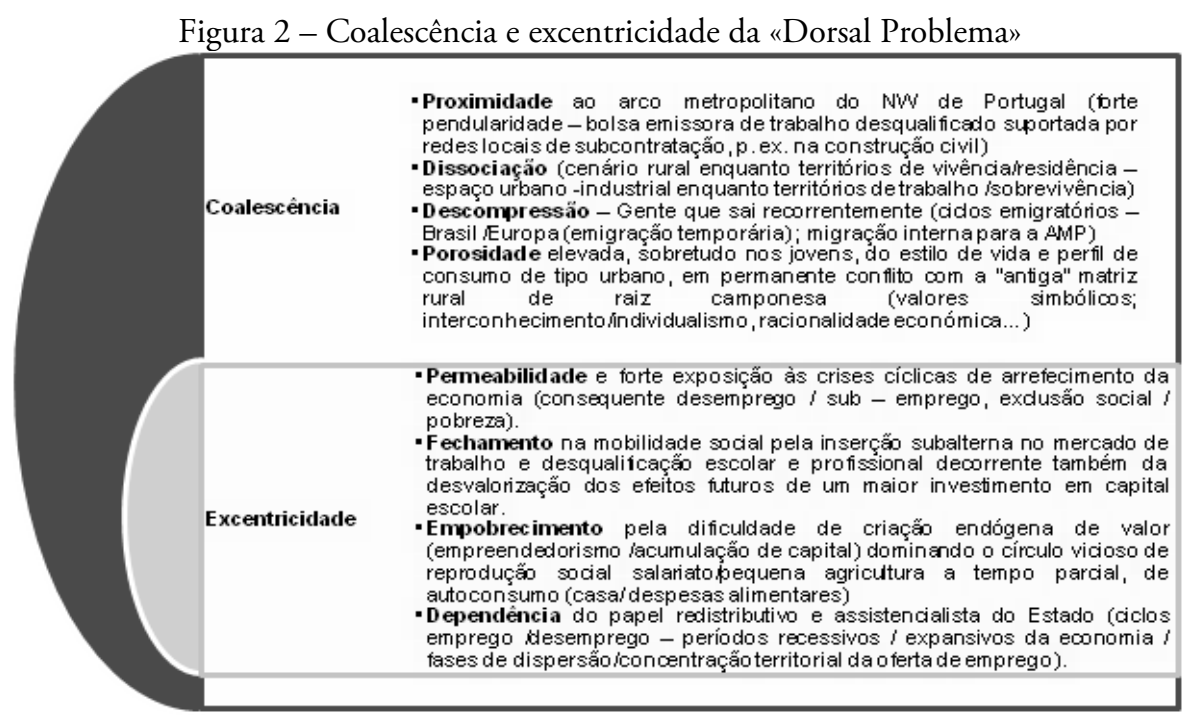

A NUT III Tâmega corresponde ao território português de menor PIB per capita, pouco mais de metade $(54 \%)$ da média nacional (2004), apresentando um índice de poder de compra em relação à média nacional de $61.4 \%$ (2007). Com um contributo de apenas 2.9 $\%$ para o PIB português, o emprego na indústria de média e alta tecnologia no emprego industrial total era apenas de $4 \%$ e o peso relativo do emprego nas TIC no total do emprego era ainda menor $(0.4 \%)$, significativamente os valores mais baixos da NUT II Norte.

Como se disse, a esmagadora maioria dos valores relativos à qualificação da população ou os indicadores de exclusão social são aqui particularmente preocupantes. As taxas de pré escolarização e do abandono escolar são mais negativas do que na Região Norte ou do que em Portugal, o que inevitavelmente se irá repercutir, a curto ou a médio prazo, nos níveis de formação dos futuros activos, condiçóes propícias à manutenção de handicaps vários que tendem a reproduzir um ciclo vicioso de subalternidade resistente e tendencialmente perene. Registe-se, por exemplo, a dimensão da baixa qualificação escolar dos trabalhadores por conta de outrem: cerca de $3 / 4(74.6 \%)$ era inferior ou igual ao $3^{\circ}$ ciclo do ensino básico, correspondendo a uma média de escolaridade de apenas 6.4 anos, enquanto que, em Portugal (2007), o peso relativo dos trabalhadores com o ensino obrigatório completo ou inferior era de $23.2 \%$. 

DOURO

Mas, quase todos estes indicadores são ainda mais desfavoráveis nos municípios mais excêntricos em relação Arco Metropolitano do Noroeste de Portugal, como são os casos de Baião, Resende ou Cinfães. Este último município, comunga com os restantes uma matriz rural dominante em processo acelerado de perda demográfica e de crescente envelhecimento populacional, particularmente evidente desde a década de 50, como resultado quer das migraçóes para o litoral quer, sobretudo, do fluxo emigratório europeu.

A elevada taxa de desemprego e desemprego de longa duração, embora não muito distante da média da NUT II Norte, é potenciada pela recorrente precariedade do mercado de trabalho, ao que acrescem as elevadas taxas de alcoolismo e, mais recentemente, pela maior porosidade urbana, de toxicodependência, tudo reflectindo-se num dos mais baixos índices de poder de compra (49.3\%) que se registam a nível nacional.

O desemprego registado em Julho de 2009 atingia no município de Cinfães 1364 pessoas, sendo o feminino (771) superior ao masculino (593), num peso relativo semelhante, quanto ao género, ao que ocorria, na mesma data, na NUT II Região Norte (43\% homens e $57 \%$ mulheres). Com idade inferior a 25 anos havia 175 jovens, o que representava $12.8 \%$ do total e com 55 anos ou mais (18.7\%), ou seja, uma repartiçáo por escalóes etários semelhante à que registava a Região Norte. A estrutura do desemprego, segundo os níveis de escolaridade, está em consonância com a desqualificação dominante. Do total de desempregados, quase metade $(48.2 \%)$ tinha como habilitaçóes apenas o $1^{\circ}$ ciclo ou ainda menos, o que é elucidativo, e dos remanescentes ainda $25.3 \%$ tinham completado apenas o $2^{\circ}$ ciclo, ou seja, seis anos de escolaridade, valores relativos superiores aos registados para o conjunto da Regiáo Norte, a qual, apesar de um perfil igualmente desqualificado, ainda assim se mostra bem mais brando, na medida em que para o primeiro ciclo o valor relativo era de $39.7 \%$ a que acrescia $20.6 \%$. Ou seja, se na Região Norte cerca de $2 / 3$ dos desempregados $(60.3 \%)$ tem 6 ou menos anos de escolaridade, em Cinfães esse valor sobe para cerca de $3 / 4(73.5 \%)$.

Some-se agora, além da elevada taxa de abandono escolar, a baixa qualificação escolar/profissional dos mais jovens. Cinfáes ocupava, em 2001, o $4^{\circ}$ lugar no abandono escolar no ranking do país, com saída antecipada da escola de 52,6\% (40 concelho com valor mais alto), saída precoce de $68,2 \%$ - $8^{\circ}$ lugar; e taxa de retençáo de $13,6 \%$ - 3 o lugar².

Cinfães é também um território marcado por dinâmicas de envelhecimento populacional e de aumento dos índices de dependência geracional, com uma estrutura familiar de perfil tradicional, confrontada com o aumento do número de famílias com idosos isolados, sobretudo nas freguesias mais rurais.

A variação da população residente entre 1991 e 2001, à excepçáo das freguesias de Cinfães, Souselo, Oliveira do Douro e Tarouquela, onde se situam os frágeis núcleos de condensação urbana, foi negativa. A população concentra-se sobretudo nas freguesias pertencentes à Ribeira Atlântica, que se encontram estruturadas pela EN222 e que apresentam uma maior diversidade de oferta de bens e serviços, em contraponto com as serranas, mais isoladas, em rápido processo de despovoamento.

\footnotetext{
${ }^{2}$ Câmara Municipal de Cinfã̃es (2006)
} 
Figura 3 - População residente e densidade populacional no município de Cinfães, por freguesia em 2001

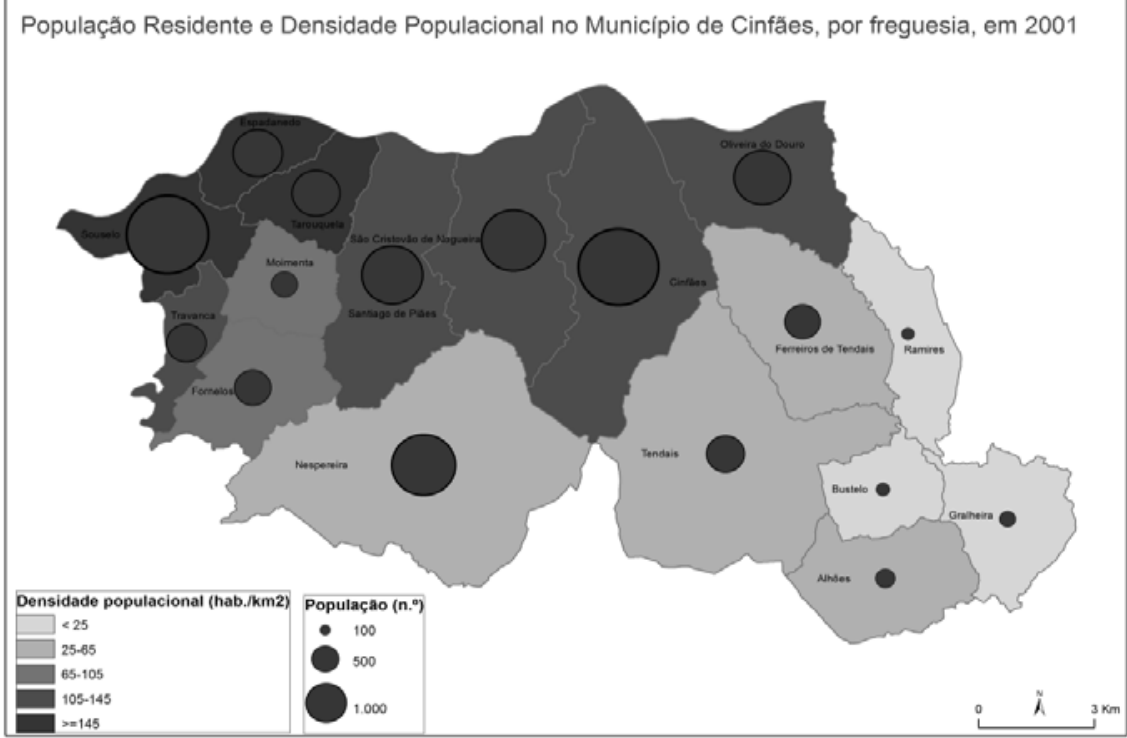

\section{A REORDENAÇÃO DA REDE ESCOLAR NO PROCESSO DE DESENVOLVIMENTO}

A inclusão social e a promoção de competências passam inevitavelmente e, em primeiro lugar, pela assunçáo de uma «cultura de desenvolvimento» ${ }^{3}$, tendo um papel fundamental a interacção das redes e a acção educativa. Se a população local é, necessariamente, o principal actor do processo de desenvolvimento, não é a única responsável pela criação do modelo tripartido pós produtivista assente na "eco-socio-economia» ${ }^{4}$ e na multifuncionalidade dos territórios da ruralidade.

Vários autores ${ }^{5}$ que têm efectuado estudos empíricos aplicados, analisando os impactes do encerramento de escolas na coesão social das regióes, têm invariavelmente concluído que a rede escolar é decisiva para o desenvolvimento sustentado dos territórios e para a coesão social dos espaços rurais.

Amiguinho ${ }^{6}$ refere que o reordenamento da rede escolar só tem sentido se os projectos educativos forem congruentes com as matrizes socioculturais em que se territorializam, favorecendo a "promoção dos valores locais e das raízes, a reconstrução de identidades sócio-pessoais e locais, a produção de sociabilidades e o equacionamento e solução de problemas comuns». Já anteriormente, em 1999, João Ferrão ${ }^{7}$, defendia que a reorganização da rede escolar do $1^{\circ}$ ciclo devia ter em consideração o encerramento dos esta-

\footnotetext{
${ }^{3}$ Melo (1994)

${ }^{4}$ Covas (2007)

${ }^{5}$ Witten et al (2001)

${ }^{6}$ Amiguinho (2005)

${ }^{7}$ Ferrão (1999)
} 
belecimentos, a recentralização de escolas com melhores acessibilidades, a constituição de redes de escolas próximas, tendo sempre como referência a mobilidade dos alunos, docentes, ou a integração em equipamentos multiuso, entre outras redes de apoio.

As cartas educativas têm como intuito racionalizar, planear e redimensionar recursos de acordo com a Lei de Bases do Sistema Educativo, procurando-se diminuir as assimetrias inter e intra-regionais, promover o desenvolvimento económico, urbanístico e sociocultural de forma coesa, optimizando sempre os recursos endógenos, materiais e imateriais, de determinada regiáo. O papel da comunidade educativa e dos projectos educativos de escola são, neste aspecto, essenciais ao promoveram uma cultura e uma prática de participaçáo. A escola, enquanto agente de socialização, assume-se como um dos pilares na estratégia de promoção do desenvolvimento. A sua relaçáo com as redes locais, os processos de participação e a valorização do conhecimento erudito, memória e identidade locais são aspectos fulcrais, sendo sempre necessário um acordo de convergência que inclua a governança, nomeadamente pela definição das modalidades de participação democrática.

\section{INCLUSÃO SOCIAL, QUALIFICAÇÃO, REDE ESCOLAR - CINFÃES DO DOURO}

Territorializar os saberes, saber, saber ser, estar e agir é fundamental para a sustentabilidade de um processo de desenvolvimento, o que implica repensar as práticas da escola, tentando alargar a sua acçáo no território (comunidade) e no tempo (aprendizagem ao longo da vida). É, por isso, cada vez mais importante pensar a rede educativa de forma abrangente e entrecruzada, não só enquanto infra-estrutura, mas também na sua dupla funçáo educacional e de agente de desenvolvimento.

Figura 4 - Parque escolar 2005/06, conjuntos de paisagem e rede viária do município de Cinfães

Parque escolar 2005/2006, conjuntos de paisagem e rede viária do municipio de Cinfães

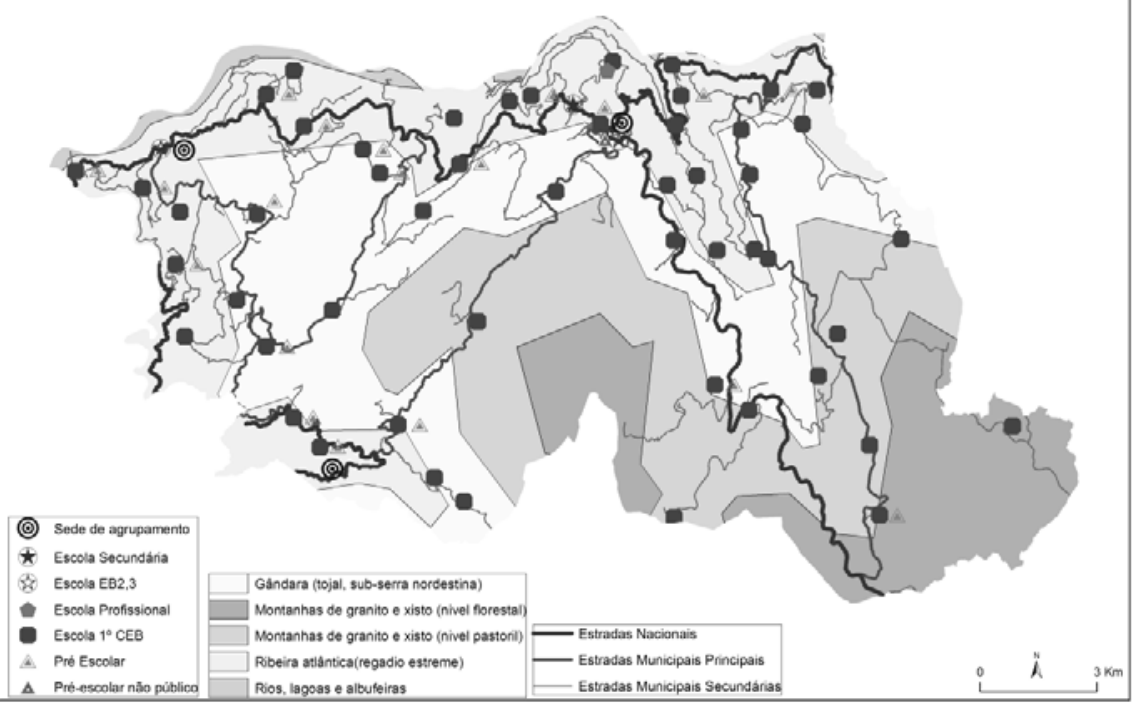


Em 2005/2006, existiam no município de Cinfães três agrupamentos (Cinfães, Souselo e Nespereira) existindo um parque escolar do $1^{\circ}$ Ciclo do Ensino Básico (CEB) descentralizado já que todas as freguesias tinham, pelo menos, uma escola.

A diminuição sistemática do número de alunos do $1^{\circ} \mathrm{CEB}$ agravou-se nos últimos anos, registando-se desde o início da década de 90, um decréscimo de aproximadamente 50\%. Das 51 escolas do 10 CEB existentes no ano lectivo 2005/2006, 23 tinham uma presença inferior a 10 alunos e 8 menos de 5 alunos, sendo que a maioria das escolas tinha uma taxa de ocupação inferior a 50\%. Acresce a notória falta de condiçóes básicas para o sucesso das actividades lectivas e para a sua diversificaçáo.

No ano lectivo 2009/2010, a reorganização do «mapa do parque escolar» está praticamente concluído, passando a existir apenas dois agrupamentos de escolas (Cinfấes e Souselo).

Figura 5 - Parque escolar 2009/10, conjuntos de paisagem e rede viária do município de Cinfães

Parque escolar 2009/2010, conjuntos de paisagem e rede viária do município de Cinfães

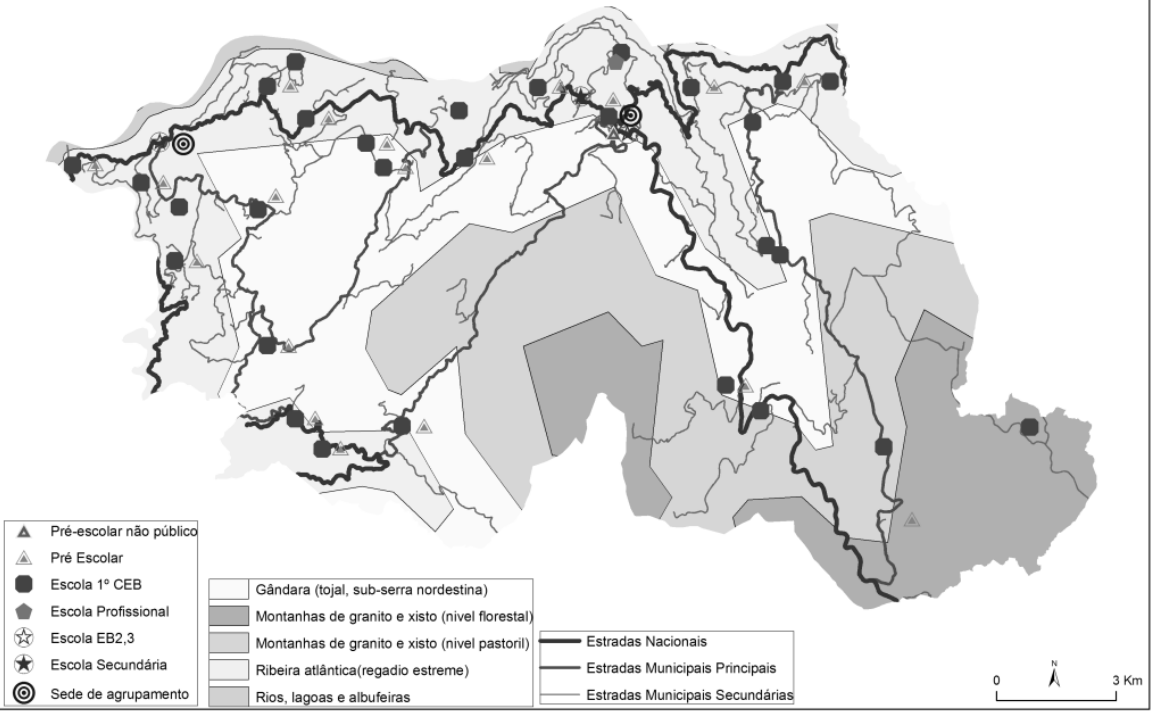

Como é evidente, o encerramento de escolas teve como consequência a mobilidade de alunos de umas escolas para outras, num mínimo de aproximadamente 900 metros e num máximo de $6,5 \mathrm{~km}$ nas freguesias serranas.

No caso específico do concelho de Cinfães, a elaboração e monitorização da Carta Educativa pelo Conselho Municipal de Educação partiu, como é evidente, do número de alunos existentes, mas atendeu também às dinâmicas e evoluçáo da populaçáo, considerando as acessibilidades e necessidades de transporte, numa tentativa de promoçáo de equidade territorial e máxima distribuição possível dos Centros Escolares.

O território contíguo aos vales dos rios Douro e Paiva, designado de Ribeira Atlântica é o mais densamente povoado, possuindo uma malha mais densa de rede viária, uma maior 
facilidade de transporte e uma morfologia menos acidentada, justamente onde ocorrem variaçôes da populaçáo positivas. É aqui que, naturalmente, se regista a maior concentração dos centros escolares. À medida que nos afastámos desta área para a serra, invertem-se as condiçôes, existindo agora freguesias sem escola do $1^{\circ} \mathrm{CEB}$ na Serra do Montemuro.

À luz das cartas educativas analisadas ${ }^{8}$, entrevistas efectuadas ${ }^{9}$ e dos princípios que regem a reorganização da rede escolar, esta mudança parece ser virtuosa. Requalificou o parque escolar, tendo sempre em conta a integração urbanística e arquitectónica das escolas, assim como as características dos diferentes níveis de ensino. Criaram-se equipamentos desportivos, além de novas condiçóes de salubridade, segurança, conforto e bem-estar. Mobilizaram-se recursos e infra-estruturas de apoio em rede com a actual sociedade da informaçáo, diversificando e melhorando as ofertas formativas, elevando a taxa de ensino pré-escolar para $100 \%$, procurando-se igualmente responder às necessidades dos alunos com necessidades educativas especiais. Para além disso, os transportes são assegurados aos alunos do $1^{\circ}, 2^{\circ}, 3^{\circ}$ CEB e Ensino Secundário, quando residam a mais de $3 / 4 \mathrm{~km}$.

O objectivo desta requalificação é melhorar efectivamente a qualidade de vida da populaçáo e do serviço educativo prestado às crianças, quer em termos das infra-estruturas de apoio quer do serviço de refeiçóes, transportes e actividades extra-curriculares e prolongamento de horários, promovendo as vivências no espaço escola, criando caminhos para o sucesso escolar e consequente diminuição do abandono.

Os meios e recursos disponíveis não se encerram na escola, podendo ser utilizados noutras actividades promotoras de uma maior inserçáo no meio local. Por exemplo, estes espaços dispóem de uma biblioteca aberta à comunidade e de uma sala específica para os encarregados de educação e associaçáo de pais, sendo igualmente os espaços desportivos do Centro Escolar abertos à comunidade.

É certo que o reordenamento da rede escolar teve como princípio basilar opçóes pedagógicas/funcionais mas, as consequências daí decorrentes ultrapassam-nas, em larga medida.

Com o objectivo estratégico de longo prazo de formar cidadáos activos, participativos e intervenientes, apostou-se no conhecimento e reconhecimento dos recursos endógenos do concelho, na transmissão de saberes ancestrais (ex. prática agrí́cola, artesanato ou cestaria), na promoção da defesa do ambiente em parceria com a Associaçáo de Defesa do Vale do Bestança através de acçốes simples como passear ao Vale do Bestança, ou visitar o Parque Eólico do Pinheiro (Montemuro).

O $1^{\circ}$ ciclo é a base da educação, a primeira barreira de socialização da criança, que deve ser eficaz, eficiente e de qualidade, sendo importante o trabalho entrecruzado de equipas multidisciplinares e a actualização incessante num Universo em constante dinâmica e mudança. Segundo as orientaçôes curriculares do $1^{\circ}$ ciclo de Ensino Básico ${ }^{10}$, "todas as crianças possuem um conjunto de experiências e saberes que foram acumulando ao longo da sua vida, no contacto com o meio que as rodeia. Cabe à escola valorizar, reforçar, ampliar e iniciar a sistematização dessas experiências e saberes (...)». A escola poderá fazê-lo a partir de todas as disciplinas mas particularmente da área de Estudo do Meio, promovendo a valorização e reprodução / enraizamento de traços identitários, do

\footnotetext{
8 Câmara Municipal de Cinfães (2006)

9 Informação recolhida em entrevistas com Fátima Sousa (Vereadora do Pelouro da Educação, Saúde e Assuntos Sociais) e a Jorge Ventura, Presidente da Associação de Defesa do Vale do Bestança

${ }^{10}$ Ministério da Educação
} 
conhecimento do meio natural, do património material e imaterial ou da paisagem, contribuindo para uma cidadania activa e participativa.

\section{CONCLUSÃO}

Castells ${ }^{11}$ sublinha que a «unidade é a rede, pelo que a arquitectura e a dinâmica de várias redes constituem as fontes de significado e função de cada local. $\mathrm{O}$ espaço dos fluxos resultante é uma nova forma de espaço (...)».

A reorganização da rede escolar do $1^{\circ} \mathrm{CEB}$ se tiver como base um planeamento criterioso pode contribuir para promover a coesão territorial e social e estabelecer nos centros escolares uma alavanca para a coesão e o futuro desenvolvimento local, através da abertura e flexibilidade ao meio, à comunidade, de aplicabilidade do curriculum e promoçáo e valorização dos traços de um concelho. O que se pretende é um desenvolvimento baseado nos desafios do futuro, da educação, da globalização, da conexão das redes e da coesão.

\section{REFERÊNCIAS BIBLIOGRÁFICAS}

Amiguinho, Abílio (2005): Educação em meio rural e desenvolvimento; Revista Portuguesa de Educação, Universidade do Minho

Câmara Municipal de Cinfầes (2006): Carta Educativa do Concelho de Cinfäes

Castells, Manuel (2004): A Galáxia Internet, Reflexóes sobre Internet, Negócios e Sociedade, Fundação Calouste Gulbenkian, Lisboa

CCDRN (2009): Plano Regional de Ordenamento do Território do Norte (Modelo Territorial)

CEDRU (2008) Programa de Acção Intermunicipal de Serviços Colectivos de Proximidade 2007-2010 Tâmega, Relatório Final Preliminar

Covas, António (2007): Temas e Problemas do Mundo Rural - Ruralidades I; Universidade do Algarve

DGOTDU (2007): Programa Nacional da Política de Ordenamento do Território.

Ferrão, João (1999): Relaçôes entre mundo rural e mundo urbano: evolução histórica, situação actual e pistas para o futuro. Sociologia, Setembro 2000, no.33, p.45-54. ISSN 0873-6529.

INE (2001) - Censos 2001 - Resultados Definitivos; INE

INE (2008) - Anuário Estatístico da Região Norte; INE

Melo, Alberto (1994) - Ruralidade e Desenvolvimento, in IDEA (Iniciativa para o Desenvolvimento, a Energia e o Ambiente), Lisboa.

Ministério da Educação: Curriculum Nacional do Ensino Básico - Competências Essenciais

PRODER (2007), Programa de Desenvolvimento Rural, 2007-2013, Ministério da Agricultura, do Desenvolvimento Rural e das Pescas

Quartenaire Portugal (2008): Nas margens do Tâmega: Mercado de Trabalho, Pobreza e Exclusão: interacçöes e intervenções; Edição REAPN

Witten, Karen; Mccreanor, Tim; Kearns, Robin \& Ramasumabramanian, Laxmi (2001), The impacts of a school closure on neighbourhood social cohesion: narratives from Invercargill, New Zealand, Health \& Place 7 (2001) 307-317

\footnotetext{
${ }^{11}$ Castells (2004)
} 